\title{
Relationship between nurses' motivation and patients' satisfaction in dialysis units in Minia city
}

\author{
Dalia Salah Ramdan ${ }^{1}$; Safaa Mohamed Abd EIrhman ${ }^{2}$; TarekA.Abdel-ELRahman ${ }^{3}$
}

1. B.Sc. Nursing

2. Professor of Nursing Administration, Faculty of Nursing, Minia University.

3. Assistant Professor of public health and preventive medicine, Faculty of Medicine, Minia University

\begin{abstract}
Background: In the health-care system, motivation is crucial for retaining healthcare workers. As a result, health-care systems become more productive, which is reflected in patient outcomes. In the nursing profession, there are various motivating patterns to consider, including rewards, relationships, challenges, control, and drive. Patient satisfaction, quality of life, symptoms, morbidity, and mortality are only a few of the health-care service's patient outcomes. Aim: To assess relation between nurses' motivation and patients' satisfaction in dialysis units. Research design: Cross sectional descriptive correlative research design. Subjects: Convenience sample, the study subjects were including nurses and patients in dialysis units with total number 447patients and 83 nurses. Setting: The study was conducted at Dialysis Units of: Minia General Hospital, Minia University Hospital and Health Insurance Hospital. Tools of data collection: included two tools; first tool Motivation factors of nurses; second tool Patient's satisfaction. Results: the majority of staff nurses $(89.2 \%)$ have moderate level of motivational factors in selected Hospitals, while (10.8\%) of them has high level of motivational factors. Moreover the majority of patients $(66 \%)$ have moderate level of satisfaction in selected Hospitals, while (34\%) of them has high level of satisfaction. Conclusion: The findings of this study revealed that positive correlation between nurses' Motivation factors and patients' satisfaction in selected Hospitals. Recommendations: The hospital should establish multidisciplinary motivation teams which will be responsible for care of the careers. The team would also be responsible in conducting meetings and facilitate in exploring other means of motivating the nurses. Moreover the nursing care should continually involve the patients in their care in order to individualize the care.
\end{abstract}

Keywords: Motivation, Nurses, Satisfaction, Patients

\section{Introduction}

Today, healthcare sector is facing stiff competition and an increasing expectation from the patients. Patients are viewing healthcare services from different angles and perspectives. Standard of healthcare services has been emphasized tremendously owing to the rising consumer affluence and well-informed patients towards the quality and delivery of healthcare services (Hee \& Kamaludin, 2016).

So motivation plays an important role in retaining healthcare personnel. This in turn increases productivity of the health care systems which is manifested in patients' outcomes. There are several motivational patterns in the nursing profession such rewards, relationship, challenge, control and drive. Patient satisfaction, quality of life, symptoms, morbidity and mortality are some of the patient outcomes in the health care service (Kantek et al., 2015).

In healthcare organization, work motivation is an important measure of healthcare professional's response to the increasing challenges and demands. Motivation is known as a process that starts with an inspiration to perform and energized to an end. It initiates behaviours to accomplish the intended goals. Motivation is a complex, multidimensional and therefore defined as "the force within individual that influence or direct behaviour (Baljoon et al., 2018).

Moreover motivation is a concept used to describe an external state inspiring a special behavior and internal responses revealing that behaviour. In the organizational context, motivation is explained as the stimulus of work behaviour, which channels the worker's effort to accomplish the organization's goals. Worker motivation is the result of the interactions between individuals (internal psychological process), their work environment (a transactional process) and the fit between these interactions and the societal context (Hee \& Kamaludin, 2016).

Extrinsic motivation (EM) is an exterior force that leads workers to meet personal and organizational aims. Moreover, it guides persons to carry out responsibilities by using coercion or instruction to get rewards in return. Extrinsic rewards consist of awards, bonuses, pay and benefits. It also can be in the forms of good relationship between workers, better facilities, good working conditions and higher administrator's quality at the work area. Extrinsic motivation in the healthcare context leads the nurses to achieve work behaviors such as prizes, positions, awards, incentives and numerous fringe benefits which generated by external stimuli and profit themselves and their organization (Papathanasiou et al., 2014).

So motivation is the willingness to put effort into achieving a goal or reward to decrease the tension caused by need. Motivated human resources are the most important assets of any health system. This resource, especially nursing department works directly with the health consumers (patients). Once the nurses are motivated, the work productivity increases resulting in good outcome which is good patients' outcomes. In recent years it has been increasingly recognized that improving the motivation of health personnel should be at the core of any sustainable solution to patient outcome (Demirhan, 2020).

Patient satisfaction with medical care is a multidimensional concept, with a dimension that corresponds to the major characteristics of providers and services. Within the health care hospital, patient satisfaction can be considered as an important component and measure of the quality of care. Patient satisfaction is a cumulative construct which embraces satisfaction with various hospital facilities such as technical, 
functional, interaction and atmosphere. Patient satisfaction plays an important role in the continuity of service utilization and positively influences the patient's trust (Bakan et al., 2014).

Patients' satisfaction reflects patients' perceptions and needs towards health service utilization. Assessing patients' satisfaction is an important since it often helps, in absence of healthcare service quality indicators, to determine the quality of health-care delivery and health system responsiveness (Batbaatar et al., 2015).

Higher levels of patients' satisfaction indicate higher levels of patient empowerment, commitment to care and compliance to recommended management-all of which results in better health outcomes. Measuring patients' satisfaction also helps to improve service delivery and to prioritize capacity building needs and resource distribution. Previous studies looked into this topic either from quality of care perspectives or from healthcare system perspectives (Adhikary et al., 2018).

Moreover chronic diseases have received increased attention from health professionals by presenting high rate of morbidity and mortality rates. Thus, it becomes a major concern for the public health field. Among the many chronic diseases that affect the population, Chronic Kidney Disease (CKD) is considered a pathology without expectation of the cure, with rapidly and progressive evolution, triggering diverse reactions for patients and compromise the quality of life (QOL). This disease is present in a large number of people and has a gradual and irreversible evolution, generating complications and disorders for patients (McCrory et al., 2018).

So dialysis care nursing is one of the developing disciplines because more and more nurses are venturing into the field. This field requires nurses who are highly knowledgeable and skilled for the care of patients with Chronic Kidney Disease. Technological and educational advances make it a dynamic field, rich with a wide variety of career opportunities for a new graduate or an experienced practitioner (Moffatt et al., 2018).

\section{Significance of the study}

During the researcher work in Minia General Hospital, observed that dialysis nurses had frustration in their work manifested with repeated absenteeism from work, unthinking in new ideas associated with dialysis, committed a lot of mistakes and taking many functional sanctions which lead to patient's dissatisfaction. So, it is helpful to investigate the relationship between nurses' motivation and patients' satisfaction.

Over the last years, Patient satisfaction has been increasingly used as one indicator of the quality of health care. Measurement of patient satisfaction is used to compare health care programs and to evaluate quality of care and to identify which aspect of a service need improvement suggested that patient satisfaction is an important and widely accepted measure of care efficiency(Simeza, 2013).

There were no previous studies which linked those two interrelated variables together, but Aly and ElShanawany, (2016) studied the influence of performance appraisal satisfaction on nurses' motivation and their work outcomes in critical care and toxicology units, the study conducted on 14 critical care and toxicology units within the Alexandria University Hospitals and indicated that nurses' intrinsic motivation had a highly significant positive relationship with nurses' work outcomes. while Fouad et al., (2020) studied nurses compliance toward patients' rights and its relation to patients satisfaction, the study conducted at Minia and indicated that more than half of staff nurses had high level of compliance toward patients' rights and low half of patients responded toward high level of satisfaction at Minia University Hospital

Moreover Simeza,. (2013) studied Impact of nurses' motivation on patients' outcomes: a case study of renal unit at Kenyatta National Hospital $(\mathrm{KNH})$. The study revealed that nurses in renal unit of KNH are motivated with achievement, recognition, autonomy and renumeration. The patients were satisfied with nurses' good listening skills, being treated as individuals, nurses' responsiveness, and provision of information.

\section{Aim of the study}

The study aim to assess relation between nurses' motivation and patients' satisfaction in dialysis units with the following specific aims :

- To assess the patient' satisfaction in dialysis units.

- To determine the motivational factors of nurses working in dialysis units.

- To examine the relationship between nurses motivation and patient satisfaction.

\section{Research questions}

- How to reach patients' satisfaction in dialysis units?

- What are the motivation factors of nurses working in dialysis units?

- Is there a relationship between nurses motivation and patient satisfaction?

\section{SUBJECTS and METHOD \\ Research Design}

Cross sectional descriptive correlational research design that was carried out in the present study.

\section{Setting}

The study was conducted at Dialysis Units in Minia General Hospital, Minia University Hospital and Health Insurance Hospital.

\section{Subjects}

Convenience sample, the study subject were including nurses and patients in dialysis units with total number 83 nurse and patients included through six months across the three hospitals as follows:

\begin{tabular}{|l|l|l|}
\hline Hospital name & $\begin{array}{l}\text { No. } \\
\text { nurses }\end{array}$ & $\begin{array}{l}\text { No. } \\
\text { patients }\end{array}$ \\
\hline Minia General Hospital & 29 & 147 \\
\hline $\begin{array}{l}\text { Minia University } \\
\text { Hospital }\end{array}$ & 31 & 150 \\
\hline Health Insurance Hospital & 23 & 150 \\
\hline Total number & $\mathbf{8 3}$ & $\mathbf{4 4 7}$ \\
\hline
\end{tabular}

\section{Tools of Data Collection}

Two tools were used in this study as follows: Motivation factors scale for nurses and Patient's satisfaction scale

$1^{\text {st }}$ tool: 
Semi-structured questionnaire for nurses was used to assess the motivational levels available in the unit; this tool was included two parts as follows:

\section{Part I: Socio demographics data}

Socio demographics data sheet for studied nurses. It was including; (age, gender, hospital name, educational level, schedule, marital status, die patients, and residence).

\section{Part II : Motivation factors of nurses scale}

The study tool had been operationalized by the researcher to suit the study with some information being modified from Whitaker, (2011) motivation scale. The modification such change 5 points Likert scale to three points (disagree $=1$; uncertain $=2$; agree $=3$ ). The motivation factors of nurses scale is self-administered. The scale consists of 19 questions attempted to determine the motivational factors for nurses and one open question for suggestions and recommendations to overall motivation levels in their department.

\section{Scoring system:}

The scoring system of this tool was classified into 3 levels as a follow: Low motivation factors of nurses ranged as (19-31), Moderate motivation factors of nurses ranged as (32-44) and High motivation factors of nurses ranged as (45-57)

$2^{\text {nd }}$ tool:

A semi - structured questionnaires were also used to collect data from the patient. This tool was included two parts as follows:

\section{Part I: Socio demographics data}

Socio demographics data sheet for studied patients. It was including; (age, gender, hospital name, educational level, Hospital length of stay, and marital status).

\section{Part II: Patient's satisfaction scale}

This tool developed by Laschinger, (2008) and was (adopted) by the researcher and translated into Arabic to assess patient's satisfaction. It include 21 questions attempt to determine patients satisfaction, each question was measured using three-points Likert scale ( $1=$ Poor, $2=$ fair $3=$ good $)$ and finally content one open question for suggestions and recommendations that enhance patient satisfaction

\section{Scoring system:}

The scoring system of this tool was classified into 3 levels as a follow: Low patient satisfaction ranged as (21-35), Moderate patient satisfaction ranged as (36-49) and High patient satisfaction ranged as(50-63)

\section{Validity of the study tools:}

Tools were tested for the content validity by a jury of three experts in the field of Nursing Administration and necessary modifications were done. The jury composed of three Assistant Professors from Faculty of Nursing, Minia University. Each of the expert panel was asked to examine the instruments for content coverage, clarity, wording, length, format and overall appearance.

\section{Reliability of the study tools}

Reliability of the tools was performed to confirm consistency of tools. The internal consistency measured to identify the extent to which the items of the tools measured the same concept and correlate with each other by Cronbach's alpha test that revealed good internal reliability for the tools; and distributed as follows:

\begin{tabular}{|cl|l|}
\hline Tools & $\alpha$ \\
\hline$\bullet \quad$ Motivation factors of nurses & 0.930 \\
\hline$\bullet \quad$ Patient's satisfaction & 0.880 \\
\hline
\end{tabular}

Pilot Study:

- A pilot study was conducted on $10 \%$ of participants as (8) of staff nurses and (45) of patients to ascertain the clarity, comprehensiveness and applicability of the tools as well as to estimate the appropriate time required to fill the scale. Based on pilot study there was no modification done, and it was added to final results.

- The main purposes of the pilot study were to:

- Test the data collection tools regarding the phrasing, and the need for adding or omitting or items for each tool

- Determine difficulties that could arise and solutions to deal with them

- Estimate time required filling the tool; it was about 10 to 15 minutes for each tool.

\section{Data Collection Procedures:}

- Official letters to obtain the approval were introduced to Faculty Dean; this letter was included a brief explanation of the objectives of the study.

- Written approvals were obtained from Directors of the three included Hospitals, and head nurses of Hospitals after explaining the purpose of the study.

- Tools were adopted and translated into Arabic; then collect the jury approval for the tools to collect data of the study.

- The tools were distributed to all the participants after explaining the purpose and process of data collection. Tools were directly administered and supervised by the researcher.

- The researcher interviewed with study participants through morning and evening shift during the working days.

- $\quad$ Participants were given from 15 minute to 30 minute to answer all the tools. They were allowed to discuss with researcher any question that needs more clarification.

- The data collection was performed from staff nurses and patients of three hospitals during the period of 6 months from the beginning of October 2018 to end of March 2019.

\section{Administrative design:}

- A written initial approval was obtained from the research ethics committee of the Faculty of Nursing, Minia University.

- An official letter was granted from Faculty Dean, the Director of the included Hospitals, and Nursing Director Hospitals

\section{Ethical Considerations:}

- The participants (staff nurses and patients) were informed that their participation in the study was completely voluntary and there was no harm if they not participate in the study. 
- Oral consent was obtained from head nurses and staff nurses after explaining the nature and benefits of the study.

- The participants assured that the data of this research will not be reused without second permission. Anonymity and confidentiality were assured .

\section{Statistical analysis of data}

Data were summarized, tabulated, and presented using descriptive statistics in the form of frequency distribution, percentages, means and the standard deviations as a measure of dispersion. A statistical package for the social science (SPSS), version (20) was used for statistical analysis of the data, as it contains the test of significance given in standard statistical books. Numerical data were expressed as mean and SD. Qualitative data were expressed as frequency and percentage. Probability (P-value) is the degree of significance, less than 0.05 was considered significant. The smaller the P-value obtained, the more significant is the result $\left.{ }^{*}\right)$, less than 0.001 was considered highly significant $(* *)$ and correlation coefficient was done by using Pearson correlation test. ANOVA test was used to compare two different mean among study and control group in the current study. Fisher's exact test: they are alternatives for the Pearson's chi square test if there were many small expected values.

\section{Results}

Table (1) distribution of the nurses staff regarding to their personal data (no. $=83$ ).

\begin{tabular}{|c|c|c|c|c|c|c|}
\hline Characteristics & $\begin{array}{l}\text { Minia } \\
\text { Hospital } \\
\text { no. }=29\end{array}$ & $\begin{array}{l}\text { General } \\
\%\end{array}$ & $\begin{array}{l}\text { Minia } \\
\text { Hospital } \\
\text { no.=31 }\end{array}$ & $\begin{array}{l}\text { Uni } \\
\%\end{array}$ & $\begin{array}{l}\text { Health } \\
\text { Hospital } \\
\text { no.=23 }\end{array}$ & $\begin{array}{l}\text { Insurance } \\
\%\end{array}$ \\
\hline \multicolumn{7}{|l|}{ Age } \\
\hline - $\quad<20 y r s$ & 2 & 6.9 & 5 & 16.1 & 7 & 30.4 \\
\hline $20<40$ yrs & 22 & 75.9 & 19 & 61.3 & 9 & 39.2 \\
\hline - $\quad 40-60 y r s$ & 5 & 17.2 & 7 & 22.6 & 7 & 30.4 \\
\hline Mean+SD = & \multicolumn{2}{|l|}{$38.16+0.364$} & \multicolumn{2}{|c|}{$39.16+0.524$} & \multicolumn{2}{|c|}{$39.16+0.214$} \\
\hline Sex & & & & & & \\
\hline Male & 17 & 58.6 & 9 & 29 & 8 & 34.8 \\
\hline - $\quad$ Female & 12 & 41.4 & 22 & 71 & 15 & 65.2 \\
\hline \multicolumn{7}{|l|}{ Educational level } \\
\hline - $\quad$ Diploma & 15 & 51.7 & 10 & 32.3 & 11 & 47.8 \\
\hline - $\quad$ Technical & 9 & 31.1 & 11 & 35.5 & 6 & 26.1 \\
\hline - $\quad$ Bachelor & 5 & 17.2 & 10 & 32.2 & 6 & 26.1 \\
\hline \multicolumn{7}{|l|}{ Marital statues } \\
\hline - $\quad$ Single & 6 & 20.7 & 4 & 12.9 & 8 & 34.8 \\
\hline - $\quad$ Married & 19 & 65.5 & 23 & 74.1 & 12 & 52.2 \\
\hline Divorced & 2 & 6.9 & 2 & 6.5 & 2 & 8.7 \\
\hline - $\quad$ Widow (Others) & 2 & 6.9 & 2 & 6.5 & 1 & 4.3 \\
\hline \multicolumn{7}{|l|}{ Schedule } \\
\hline - $\quad$ Full Time & 27 & 93.1 & 28 & 90.3 & 22 & 95.7 \\
\hline - $\quad$ Part Time & 2 & 6.9 & 3 & 9.7 & 1 & 4.3 \\
\hline \multicolumn{7}{|l|}{ Years of experience } \\
\hline - $\quad<1$ yrs. & 3 & 10.3 & 3 & 9.6 & 3 & 13 \\
\hline - $\quad 1<10$ yrs. & 11 & 37.9 & 14 & 45.2 & 6 & 26.1 \\
\hline - $10-20 y r s$. & 9 & 31 & 7 & 22.6 & 8 & 34.8 \\
\hline - $\quad>20$ yrs. & 6 & 20.7 & 7 & 22.6 & 6 & 26.1 \\
\hline Mean+SD = & $8.13+0.652$ & & $9.13+0.21$ & & $10.13+0$. & 32 \\
\hline \multicolumn{3}{|l|}{ Die patient } & & & & \\
\hline - No body & 24 & 82.8 & 17 & 54.8 & 14 & 60.9 \\
\hline $\begin{array}{ll} & 1-2 \\
\end{array}$ & 4 & 13.8 & 10 & 32.3 & 8 & 34.8 \\
\hline - $\quad 3-4$ & 1 & 3.4 & 3 & 9.7 & 0 & 0 \\
\hline - $\quad>5$ & 0 & 0 & 1 & 3.2 & 1 & 4.3 \\
\hline \multicolumn{7}{|l|}{ Residence } \\
\hline - $\quad$ Rural & 15 & 51.7 & 21 & 67.7 & 11 & 47.8 \\
\hline - Urban & 14 & 48.3 & 10 & 32.3 & 12 & 52.2 \\
\hline
\end{tabular}

Table (1) illustrates that according Minia General Hospital (75.9\%) of nurses age are ranged from 20- $<40$ years old, with mean age $38.16+0.364,(58.6 \%)$ of them are males. Concerning the education, it notes that the majority of nurses' percent $(51.7 \%)$ are diploma degree. The high percent $(65.5 \%)$ of them are married. Regarding nurses years of experience $(37.9 \%)$ are $1<10 y e a r s$, with mean $(8.13+0.652)$. Moreover $(82.8 \%)$ of them no patient die in their shift. Also $(56.6 \%)$ of them from rural area. In addition nurses at Minia University Hospital, $(61.3 \%)$ of them age are ranged from $20-<40$ years old, with mean age $39.16+0.524$, $(71 \%)$ of them are females. Concerning the education, it notes that the majority of nurses' percent $(35.5 \%)$ are technical degree. The high percent $(74.1 \%)$ of them are married. Regarding nurses years of experience (45.2\%) are 1<10years, with mean $(9.13+0.212)$. Moreover $(54.8 \%)$ of them no patient die in their shift. Also (67.7\%) of them from rural area.

Concerning Health Insurance Hospital, (39.2\%) of nurses age are ranged from $20-<40$ years old, with mean age 39.16+0.214, $(65.2 \%)$ of them are females. Concerning the education, it notes that the majority of nurses' percent (47.8\%) are diploma degree. The high percent $(52.2 \%)$ of them are married. Regarding nurses years of experience $(34.8 \%)$ are $10-20$ years, with mean (10.13+0.432). Moreover $(60.9 \%)$ of them no patient die in their shift. Also (52.2\%) of them from urban area. 
Minia Scientific Nursing Journal (Print - ISSN 2537-012X) (Online - ISSN 2785-9797) Vol. (10) No. (1) December 2021

Table (2) distribution of the patients regarding to their personal data (no. $=447)$.

\begin{tabular}{|c|c|c|c|c|c|}
\hline \multirow{2}{*}{ Characteristics } & \multirow{2}{*}{$\begin{array}{l}\text { Minia General Hospital } \\
(\text { no.=147) }\end{array}$} & \multirow{2}{*}{\multicolumn{2}{|c|}{$\begin{array}{l}\text { Minia University Hospital } \\
(\text { no.=150) } \mid \%\end{array}$}} & \multirow{2}{*}{\multicolumn{2}{|c|}{$\begin{array}{l}\text { Health Insurance Hospital } \\
(\mathbf{n o}=\mathbf{1 5 0})\end{array}$}} \\
\hline & & & & & \\
\hline \multicolumn{6}{|c|}{ 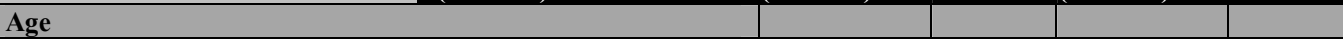 } \\
\hline - $\quad<20 \mathrm{yrs}$ & 0 & 12 & 8 & 6 & 4 \\
\hline - $\quad 20<40 \mathrm{yrs}$ & 31.3 & 46 & 30.7 & 46 & 30.7 \\
\hline $40<60 \mathrm{yrs}$ & 51.7 & 65 & 43.3 & 75 & 50 \\
\hline$>60 \mathrm{yrs}$ & 17 & 27 & 18 & 23 & 15.3 \\
\hline Mean +SD & $33.16+0.372$ & \multicolumn{2}{|c|}{$35.16+0.472$} & \multicolumn{2}{|l|}{$32.16+0.572$} \\
\hline \multicolumn{6}{|l|}{ Sex } \\
\hline - $\quad$ Male & 54.4 & 101 & 67.3 & 101 & 67.3 \\
\hline - $\quad$ Female & 45.6 & 49 & 32.7 & 49 & 32.7 \\
\hline \multicolumn{6}{|l|}{ Marital statues } \\
\hline - $\quad$ Single & 6.8 & 19 & 12.7 & 7 & 4.7 \\
\hline Married & 122 & 114 & 76 & 123 & 82 \\
\hline Divorced & 5.4 & 7 & 4.7 & 7 & 4.7 \\
\hline - $\quad$ Widow (Others) & 4.8 & 10 & 6.6 & 13 & 8.6 \\
\hline \multicolumn{6}{|l|}{ Education } \\
\hline - $\quad$ Preparatory & 21.1 & 27 & 18 & 30 & 20 \\
\hline Secondary & 26.5 & 34 & 22.7 & 45 & 30 \\
\hline High education & 35.4 & 38 & 25.3 & 45 & 30 \\
\hline - $\quad$ Others & 17 & 51 & 34 & 30 & 20 \\
\hline \multicolumn{6}{|l|}{ Hospital stay } \\
\hline - $\quad<5$ & 25.9 & 34 & 22.7 & 20 & 13.3 \\
\hline - $5-<10$ & 24.5 & 40 & 26.7 & 44 & 29.3 \\
\hline - $10-15$ & 24.5 & 44 & 29.3 & 47 & 31.4 \\
\hline - $\quad>15$ & 25.1 & 32 & 21.3 & 39 & 26 \\
\hline Mean +SD & $4.12+0.354$ & \multicolumn{2}{|l|}{ 7. $12+0.244$} & \multicolumn{2}{|l|}{$9.12+0.324$} \\
\hline
\end{tabular}

Table (2) shows that according Minia General Hospital (51.7\%) of patients age are ranged from $40-<60$ years old, with mean age $33.16+0.372,(54.4 \%)$ of patients are males. Also the majority $(83 \%)$ of them are married . Concerning the education, it notes that the majority of patients percent (35.4\%) are high education. About highest percent $(25.9 \%)$ of the hospital patients stay are $<5$ days, with mean (4. 12+0.354). In addition patients at Minia University Hospital, (43.3\%) of patients age are ranged from 40-<60 years old, with mean age $35.16+0.472,(67.3 \%)$ of patients are males. Also the majority $(76 \%)$ of them are married . Concerning the education, it notes that the majority of patients percent (25.3\%) are high education. About highest percent (29.3\%) of the hospital patients stay are 10-15 days, with mean (7. 12+0.244).

Concerning Health Insurance Hospital, $(50 \%)$ of patients age are ranged from $40-<60$ years old, with mean age $32.16+0.572$, $(67.3 \%)$ of patients are males. Also the majority $(82 \%)$ of them are married . Concerning the education, it notes that the majority of patients percent (30\%) are secondary and high education. About highest percent $(31.4 \%)$ of the hospital patients stay are $10-15$ days, with mean $(9.12+0.324)$.

Table (3) percentage distribution of nurses' opinions regarding their motivational factors in selected Hospitals (no. =83).

\begin{tabular}{|c|c|c|c|c|c|c|c|c|c|c|c|c|c|c|c|c|c|}
\hline \multirow{2}{*}{$\frac{\text { Hospitals Name }}{\text { Items }}$} & \multicolumn{6}{|c|}{$\begin{array}{l}\text { Minia General Hospital } \\
\text { (no.29) }\end{array}$} & \multicolumn{5}{|c|}{$\begin{array}{l}\text { Minia University } \\
\text { Hospital (no 31) }\end{array}$} & \multicolumn{6}{|c|}{$\begin{array}{c}\text { Health Insurance Hospital } \\
(\text { (no.23) }\end{array}$} \\
\hline & & sagree & Une & ertain & & gree & & ored & Un & n & $A$ & & agree & Unce & ertain & & gree \\
\hline Un & le & 34 & 5 & 172 & 23 & 793 & 2 & 65 & & 129 & 806 & 3 & 13 & 5 & 217 & 15 & 652 \\
\hline I tm interested working in the un & 5 & 17.2 & 8 & 27.6 & 16 & 55.2 & 5 & 16.1 & 8 & 25.8 & $18 \$ 8.1$ & 4 & 17.4 & 6 & 26.1 & 13 & 56.5 \\
\hline $\begin{array}{l}\text { 3. The certificate to be a nurse specialist is attractive for working } \\
\text { as a nurse }\end{array}$ & 2 & 6.9 & 6 & 20.7 & 21 & 72.4 & 2 & 6.5 & 4 & 12.9 & 2530.6 & 1 & 4.3 & 1 & 4.3 & 21 & 91.3 \\
\hline 4. The shifts of work affect my mood & 5 & 17.2 & 3 & 10.3 & 21 & 72.4 & 11 & 35.5 & 2 & 6.5 & $18 \$ 8.1$ & 7 & 30.4 & 3 & 13 & 13 & 56.5 \\
\hline 5. My supervis & 9 & 31 & 10 & 34.5 & 10 & 34.5 & 11 & 35.5 & 8 & 25.8 & 1288.7 & 12 & 52.2 & 7 & 30.4 & 4 & 17.4 \\
\hline 6. 61 participate in the supervisory de & 14 & 48.3 & 6 & 20.7 & 9 & 31 & 17 & 54.8 & 7 & 22.6 & \begin{tabular}{l|l|l|l|l|}
22.6 \\
\end{tabular} & 11 & 47.8 & 3 & 13 & 9 & 39.1 \\
\hline 7. I atm very satisfied with the depart & 15 & 51.7 & 7 & 24.1 & 7 & 24.1 & 9 & 29 & 8 & 25.8 & $14 \begin{array}{l}45.2 \\
\end{array}$ & 13 & 56.5 & 4 & 17.4 & 6 & 26.1 \\
\hline 8. I trotk under pressure in $\mathrm{m}$ & 13 & 44.8 & 6 & 20.7 & 10 & 34.5 & 10 & 32.3 & 8 & 25.8 & $13+1.9$ & 6 & 26.1 & 12 & 52.2 & 5 & 21.7 \\
\hline $\begin{array}{l}\text { 9. My qualifications are adequat } \\
\text { being promoted to a better pos }\end{array}$ & 4 & 13.8 & 9 & 31 & 16 & 55.2 & 4 & 12.9 & 16 & 51.6 & 1135.5 & 7 & 30.4 & 3 & 13 & 13 & 56.5 \\
\hline 10. 1 can advise my friend to join & 5 & 17.2 & 8 & 27.6 & 16 & 55.2 & 5 & 16.1 & 10 & 32.3 & 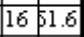 & 8 & 34.8 & 5 & 21.7 & 10 & 43.5 \\
\hline 11. I am very & 2 & 6.9 & 7 & 24.1 & 20 & 68 & 2 & 6.5 & & 22.6 & \begin{tabular}{|l|l|}
22 & 71 \\
\end{tabular} & 1 & 4.3 & 6 & 26.1 & 16 & 69.6 \\
\hline $\begin{array}{l}\text { 12. My supervis or closely observes my interaction with my patients } \\
/ \text { colleagues }\end{array}$ & 16 & 55.2 & 9 & 31 & 4 & 13.8 & 20 & 64.5 & 6 & 19.4 & \begin{tabular}{|c|c|c|c|c|} 
& 6.1 & 6
\end{tabular} & 14 & 60.9 & 3 & 13 & 6 & 26.1 \\
\hline 13. I teceive a feeling of accomplishme & 12 & 41.4 & 11 & 37.9 & 6 & 20.7 & 21 & 67.72 & 2 & 6.5 & & 15 & 65.2 & 5 & 21.7 & 3 & 13 \\
\hline 14. My sup & 11 & 37.9 & 8 & 27.6 & 10 & 34.5 & 15 & 48.4 & 6 & 19.4 & 1022.3 & 7 & 30.4 & 8 & 34.8 & 8 & 34.8 \\
\hline 15. The job & 8 & 27.6 & 9 & 31 & 12 & 41.4 & 17 & 54.8 & 9 & 29 & \begin{tabular}{|l|l|}
5 & 6.1 \\
\end{tabular} & 9 & 39.1 & 4 & 17.4 & 10 & 43.5 \\
\hline $\begin{array}{l}\text { 16. I am free to make decisions to my daily work and to act on } \\
\text { th eem }\end{array}$ & 14 & 48.3 & 8 & 27.6 & 7 & 24.1 & 14 & & & 32.3 & 722.6 & 15 & 65.2 & 4 & 17.4 & 4 & 17.4 \\
\hline 17. I am satisfied with my pres & 23 & 79.3 & 3 & 10.3 & 3 & 10.3 & 25 & 80.6 & 4 & 12.9 & \begin{tabular}{|l|l|}
2 & 6.5 \\
\end{tabular} & 22 & 95.7 & 0 & 0 & 1 & 4.3 \\
\hline 18. Wy relationship with my fellow $\mathrm{co}$ & 4 & 13.8 & 3 & 10.3 & 22 & 75.9 & 11 & 35.5 & 6 & 19.4 & $14 \begin{array}{l}45.2 \\
\end{array}$ & 3 & 13 & 2 & 8.7 & 18 & 78.3 \\
\hline 19. Patient satisfaction motivates me more & 1 & 3.4 & 1 & 3.4 & 27 & 93.1 & 2 & 6.5 & 5 & 16.1 & & 1 & 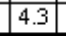 & 3 & 13 & 19 & 82.6 \\
\hline
\end{tabular}

Table (3) indicates that the majority of nurses' opinions regarding their motivational factors at Minia General Hospital response to agree for the items (Patient satisfaction motivates me more; understand what is required of me in this department; my relationship with my fellow colleagues is very good; the certificate to be a nurse specialist is attractive for working as a nurse; and the shifts of work affect my mood) as $(93.1 \% ; 79.3 \% ; 75.9 \% ; 72.4 \%$; and $72.4 \%)$ respectively, while the majority of them disagree for 
item (I am satisfied with my present salary) as (79.3\%). Moreover the majority of nurses' opinions regarding their motivational factors at Minia University Hospital in favor to agree for the items (understand what is required of me in this department; the certificate to be a nurse specialist is attractive for working as a nurse; and Patient satisfaction motivates me more) as (80.6\%;80.6\%; and $77.4 \%$ ) respectively, while the majority of them disagree for item (I am satisfied with my present salary) as (80.6\%).

Also the majority of nurses' opinions regarding their motivational factors at Health Insurance Hospital in favor to agree for the items(the certificate to be a nurse specialist is attractive for working as a nurse; Patient satisfaction motivates me more; and my relationship with my fellow colleagues is very good) as $(91.3 \% ; 82.6 \%$; and $78.3 \%)$ respectively, while the majority of them disagree for item (I am satisfied with my present salary) as (95.7\%).

Figure (1) explains that (37.8\%) of nurses' recommendations regarding their motivational factors at Minia General Hospital increase the salary, and (20.8\%) of the share in decision. While figure (2) mentions that the high percent (41.9\%) of nurses' recommendations regarding their motivational factors at Minia University Hospital provide training and (35.5\%) of them increase the salary. Moreover figure (3) mentions that the high percent $(39.2 \%)$ of nurses' recommendations regarding their motivational factors at Health Insurance Hospital provide increase number of staff nurses, and (30.4\%) of them increase the salary.

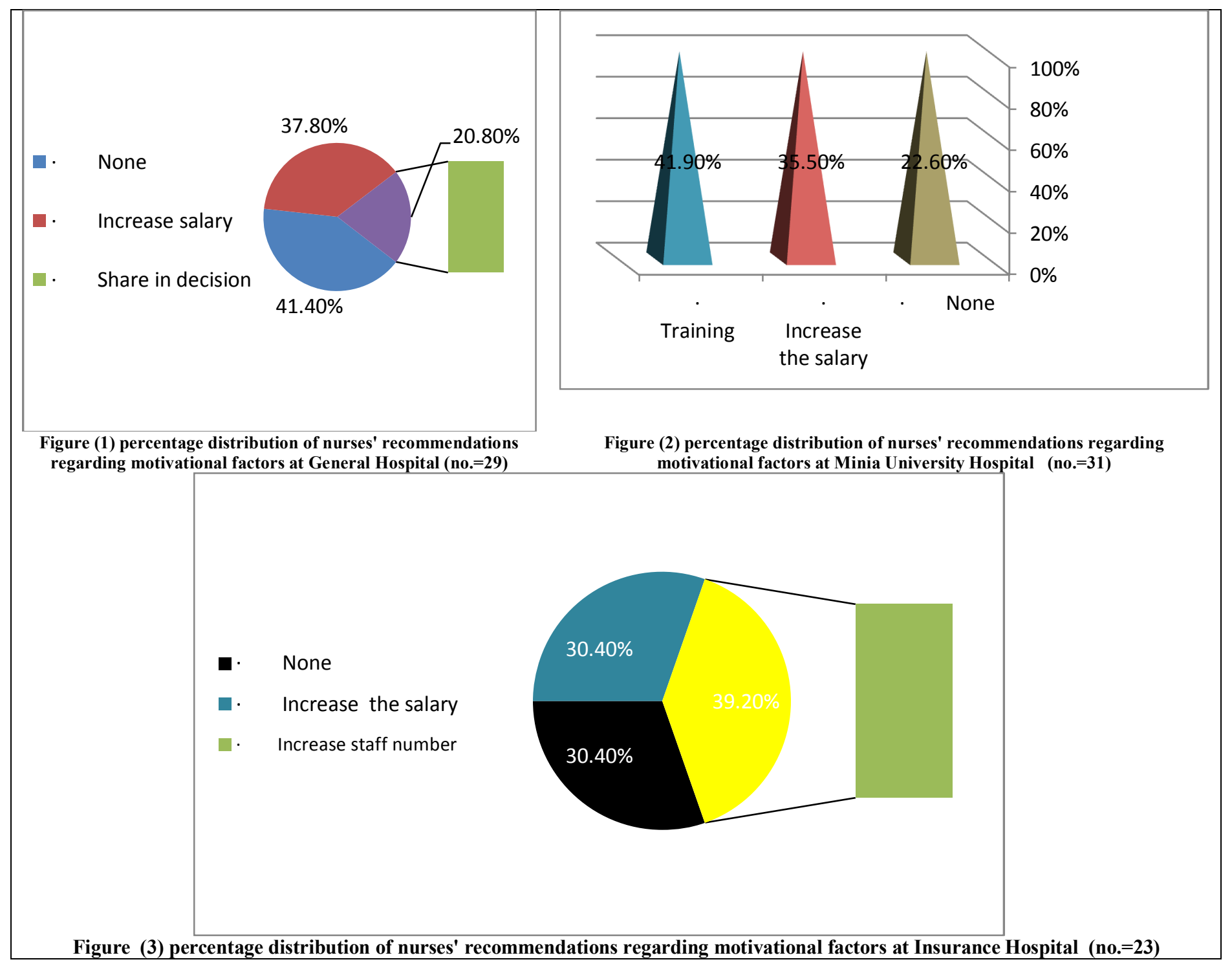




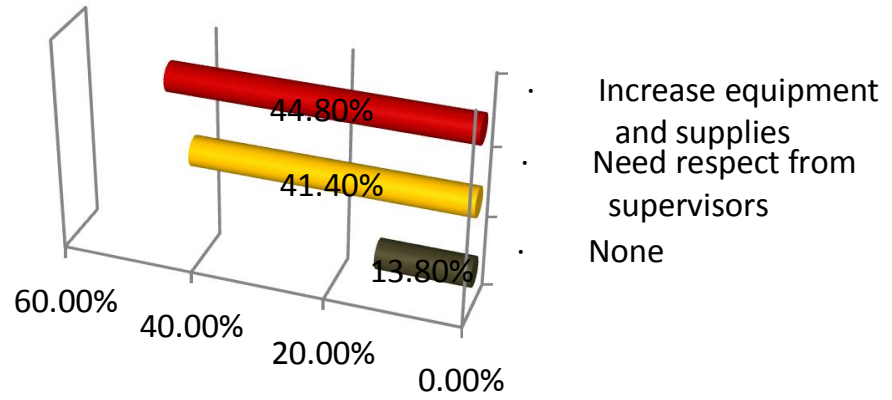

Figure (4) percentage distribution of nurses' suggestions regarding their motivational factors at General Hospital (no.=29)

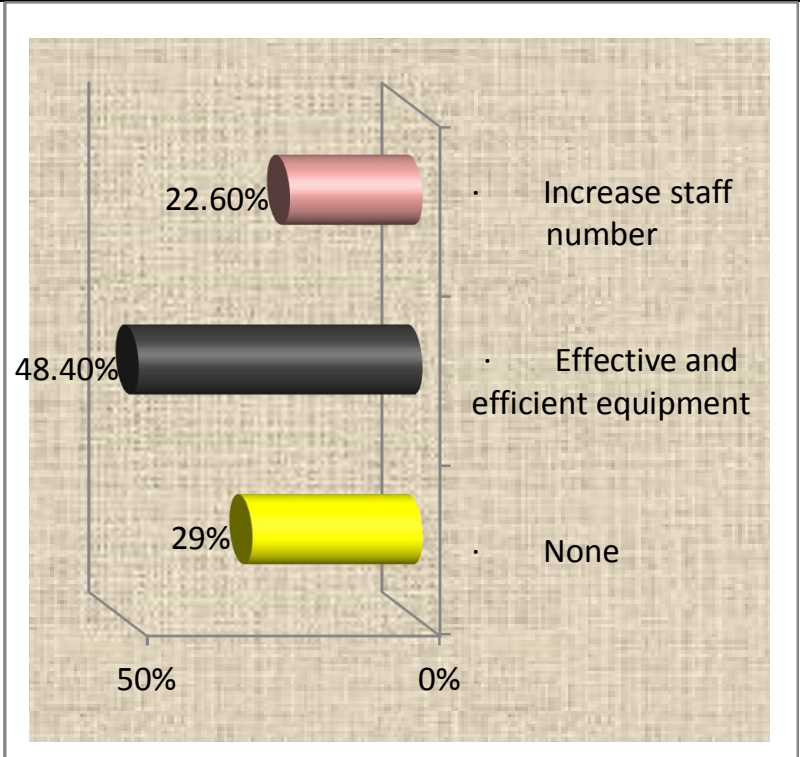

Figure (5) percentage distribution of nurses' suggestions regarding their motivational factors at Minia University Hospital $($ no. $=31)$

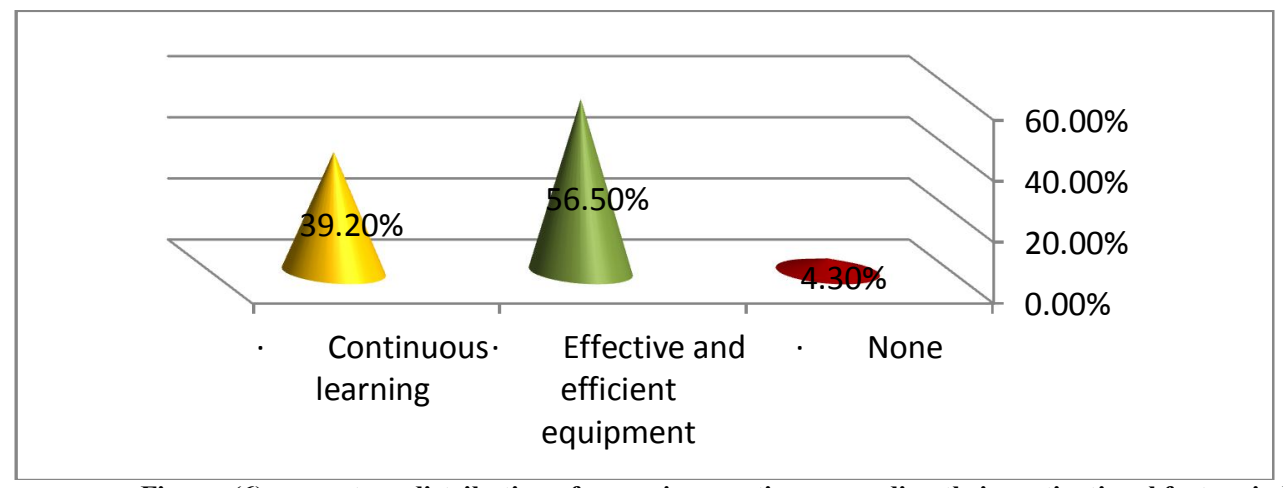

Figure (6) percentage distribution of nurses' suggestions regarding their motivational factors in Insurance Hospital (no.=23) at

Figure (4) show that the most of nurses' suggestions regarding their motivational factors at Minia General Hospital are increase equipment and supplies as $(44.80 \%)$, while $(41.40 \%)$ of them need respect from supervisors. Figure (5) explains that the most of nurses' suggestions regarding their motivational factors at Minia University Hospital are provide effective and efficient equipment as $(48.4 \%)$, while $(22.6 \%)$ of them need for increasing number of staff nurses. Moreover figure (6) discuss that the most of nurses' suggestions regarding their motivational factors at Health Insurance Hospital are provide effective and efficient equipment as $(56.5 \%)$, while $(39.2 \%)$ of them need for continuous learning.

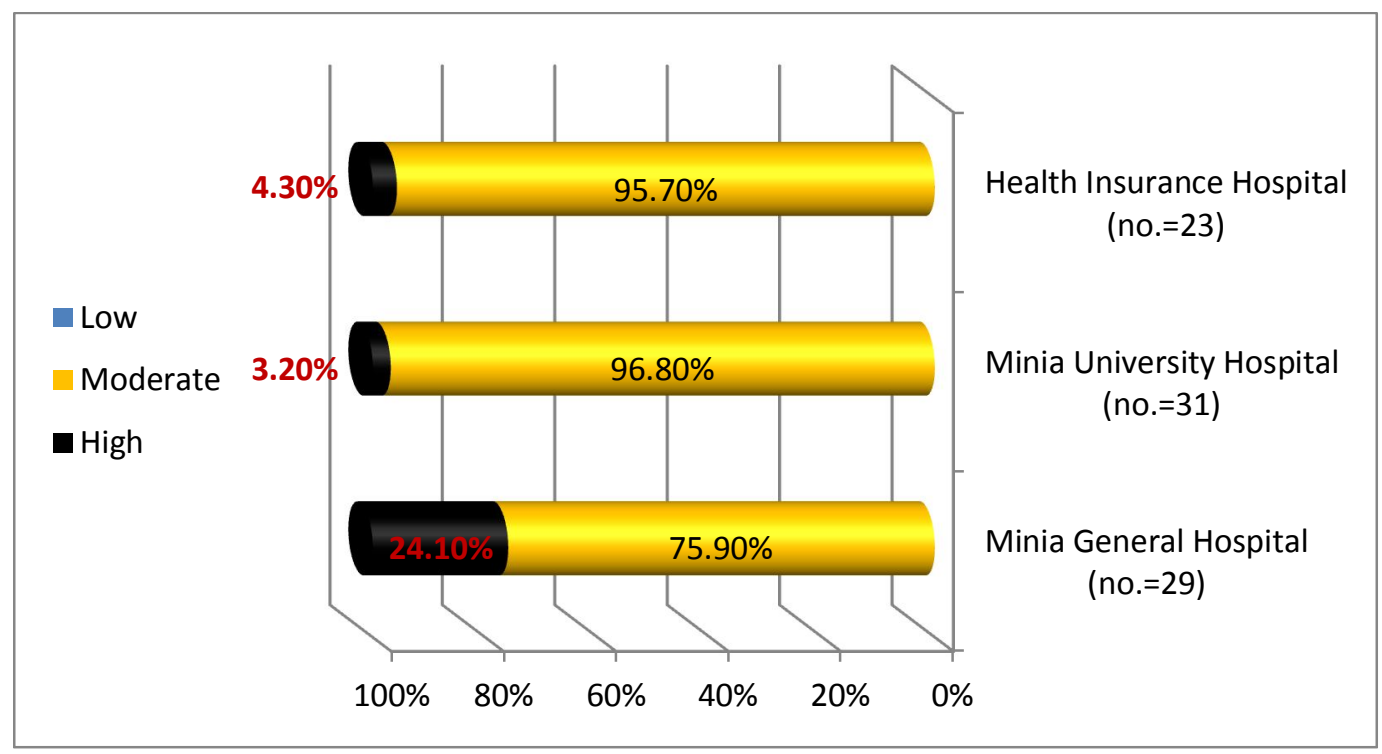

Figure (7) percentage distribution of nurses' motivational factors in selected Hospitals $($ no. $=83)$

Figure (7) shows that the majority of nurses (96.8\%) have moderate level of motivational factors at Minia University Hospital follow by nurses in Health Insurance Hospital as (95.7\%), and finally nurses in Minia Hospital as (75.9\%). 


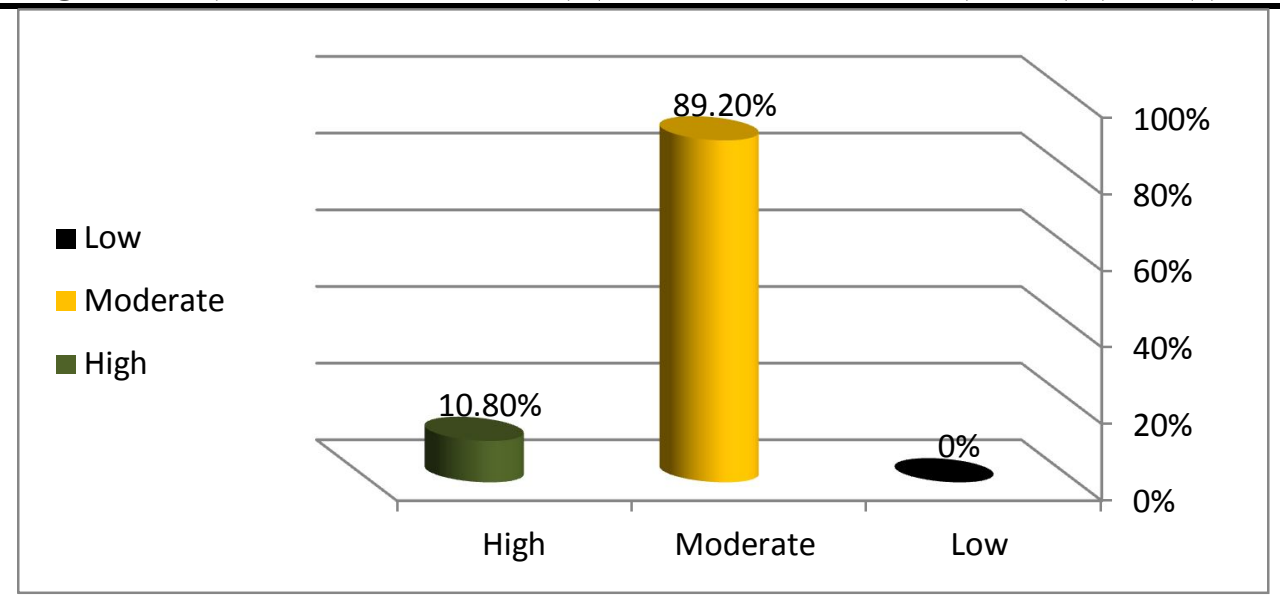

Figure (8) percentage distribution of nurses' total motivational factors in selected Hospitals $($ no. $=83)$

Figure (8) explains that the majority of nurses (89.2\%) have moderate level of motivational factors in selected Hospitals, while $(10.8 \%)$ of them has high level of motivational factors.

able (4) percentage distribution of patient's opinions regarding their satisfaction in selected Hospitals (no. =447)

\begin{tabular}{|c|c|c|c|c|c|c|c|c|c|c|c|c|c|c|c|c|c|c|}
\hline \multirow{3}{*}{ Items } & \multicolumn{6}{|c|}{$\begin{array}{l}\text { Miria General Hospital } \\
(\text { no.29) }\end{array}$} & \multicolumn{6}{|c|}{$\begin{array}{l}\text { Minia University } \\
\text { Hospital (no_31) }\end{array}$} & \multicolumn{6}{|c|}{$\begin{array}{c}\text { Health Insurance Hespital } \\
(\text { (no.23) }\end{array}$} \\
\hline & \multicolumn{2}{|c|}{ Poor } & \multicolumn{2}{|c|}{ Fair } & \multicolumn{2}{|c|}{ Good } & \multicolumn{2}{|c|}{ Poor } & \multicolumn{2}{|c|}{ Fair } & \multicolumn{2}{|c|}{ Good } & \multicolumn{2}{|c|}{ Poor } & \multicolumn{2}{|c|}{ Fair } & \multicolumn{2}{|c|}{ Good } \\
\hline & & & & & & & & & & & & & & & & & & \\
\hline 1.The nirse treated me with respect. & 30 & 20.4 & 55 & 37.4 & 62 & 42.2 & 30 & 20 & 59 & 39.3 & 61 & 40.7 & 24 & 16 & 52 & 34.7 & 74 & 49.3 \\
\hline 2.The nisse was frendly and warm towards me. & 23 & 15.6 & 47 & 32 & 77 & 52.4 & 20 & 13.3 & 53 & 35.3 & 77 & 51.3 & 21 & 14 & 41 & 27.3 & 88 & 58.7 \\
\hline 3.The nirse was not cold or abrupt towards me. & 32 & 21.8 & 46 & 31.3 & 69 & 46.9 & 28 & 18.7 & 83 & 55.3 & 39 & 26 & 39 & 26 & 80 & 53.3 & 3 & 20.7 \\
\hline 4.The nuise gave me time to fully describe my illness in myown words. & 34 & 23.1 & 77 & 52.4 & 36 & 24.5 & 18 & 12 & 59 & 39.3 & 73 & 48.7 & 19 & 12.7 & 46 & 30.7 & 85 & 56.7 \\
\hline $\begin{array}{l}\text { 5.The nirse was not interrupting or diverting me when I was talking to } \\
\text { him her }\end{array}$ & 41 & 27.9 & 71 & 48.3 & 35 & 23.8 & 36 & 24 & 72 & 48 & 42 & 28 & 38 & 25.3 & 83 & 55.3 & 29 & 19.3 \\
\hline 6.The nisse listened attentively to what I was saying & 23 & 15.6 & 33 & 22.4 & 91 & 61.9 & 21 & 14 & 42 & 28 & 87 & 58 & 13 & 8.7 & 52 & 34.7 & 85 & 56.7 \\
\hline 7.looking at the notes or computer or anything around herself & 69 & 46.9 & 49 & 33.3 & 29 & 19.7 & 81 & 54 & 45 & 30 & 24 & 16 & 91 & 60.7 & 31 & 20.7 & 28 & 18.7 \\
\hline 8.The nurse addressed me with my name not just as "just a number" & 50 & 34 & 22 & 15 & 75 & 51 & 46 & 30.7 & 42 & 28 & 62 & 41.3 & 36 & 24 & 12 & 8 & 19 & 68 \\
\hline 9.The nirse asked me the relevant details about my situation /life. & 29 & 19.7 & 69 & 46.9 & 49 & 33.3 & 23 & 15.3 & 75 & 50 & 52 & 34.7 & 31 & 20.7 & 68 & 45.3 & 5 & 34 \\
\hline $\begin{array}{l}\text { 10.The hurse communicated that helshe had accurately understood my } \\
\text { concems. }\end{array}$ & 27 & 18.4 & 49 & 33.3 & 71 & 48.3 & 13 & 8.7 & 30 & 20 & 107 & 71.3 & 16 & 10.7 & 31 & 20.7 & 19 & 68.7 \\
\hline 11.The rurse was genuinely concemed with rny situation. & 12 & 8.2 & 40 & 27.2 & 95 & 64.6 & 25 & 16.7 & 49 & 32.7 & 76 & 50.7 & 22 & 14.7 & 35 & 23.3 & 93 & 62 \\
\hline $\begin{array}{l}\text { 12.The nurse was able to connect with me on a human level, not being } \\
\text { in different or detached. }\end{array}$ & 24 & 16.3 & 64 & 43.5 & 59 & 40.1 & 28 & 18.7 & 40 & 26.7 & 82 & 54.7 & 28 & 18.7 & 36 & 24 & 86 & 57.3 \\
\hline 13.The rurse was positively approaching me with positive attitudes. & 26 & 17.7 & 33 & 22.4 & 88 & 59.9 & 43 & 28.7 & 50 & 33.3 & 57 & 38 & 17 & 11.3 & 29 & 19.3 & 164 & 69.4 \\
\hline 14.The rurse was honest about my condition. & 19 & 12.9 & 31 & 21.1 & 97 & 66 & 19 & 12.7 & 43 & 28.7 & 88 & 58.7 & 51 & 34 & 23 & 15.3 & 75 & 50.7 \\
\hline 15.The rurse was fully answering rny questions. & 31 & 21.1 & 26 & 17.7 & 90 & 61.2 & 13 & 8.7 & 31 & 20.7 & 106 & 70.7 & 17 & 11.3 & 47 & 31.3 & 85 & 57.4 \\
\hline 16.1The nurse was explaining clearly what I was supposed to do. & 0 & $\mathbf{0}$ & 41 & 27.9 & 106 & 72.1 & 24 & 16 & 47 & 31.3 & 79 & 52.7 & 23 & 15.3 & 29 & 19.3 & 98 & 65.4 \\
\hline 17.The rivse was giving me true and adequate information. & 33 & 22.4 & 47 & 32 & 67 & 45.6 & 51 & 34 & 30 & 20 & 69 & 46 & 21 & 14 & 29 & 19.3 & 160 & 66.7 \\
\hline 18.1The nurse explored with me what I could do to improve my health. & 29 & 19.7 & 26 & 17.7 & 92 & 62.6 & 20 & 13.4 & 35 & 23.3 & 95 & 63.3 & 16 & 10.7 & 53 & 35.3 & 81 & 54 \\
\hline 19. The turse was encouraging not lecturing on me. & 18 & 12.2 & 47 & 32 & 82 & 55.8 & 35 & 23.4 & 53 & 35.3 & 62 & 41.3 & 19 & 12.7 & 35 & 23.3 & $9 ;$ & 64 \\
\hline 20.The rurse discussed the options and involved me in decision making. & 40 & 27.2 & 32 & 21.8 & 75 & 51 & 39 & 26 & 44 & 29.3 & 67 & 44.7 & 24 & 16 & 34 & 22.7 & 92 & 61.3 \\
\hline 21. How would you rate your interaction with your nurse today? & 20 & 13.6 & 50 & 34 & 77 & 52.4 & 18 & 12 & 37 & 24.7 & 95 & 63.3 & 20 & 13.3 & 45 & 30 & 85 & 56.7 \\
\hline
\end{tabular}

Table (4) indicates that the high percent of patient's opinions regarding their satisfaction at Minia General Hospital in favor to good response for the items (the nurse was explaining clearly what I was supposed to do; the nurse was honest about my condition; and the nurse was genuinely concerned with my situation) as $(72.1 \% ; 66 \%$; and $64.6 \%)$ respectively, while (46.9\%) of them poor response for item (looking at the notes or computer or anything around herself). Also the high percent of patient's opinions regarding their satisfaction at Minia University Hospital in favor to good response for the items (the nurse communicated that he/she had accurately understood my concerns; and the nurse was fully answering my questions) as (71.3\%and 70.7\%) respectively, while (34\%) of them poor response for item (the nurse was giving me true and adequate information).

Moreover the high percent of patient's 'opinions regarding their satisfaction at Health Insurance Hospital in favor to good response for the items (the nurse was positively approaching me with positive attitudes; the nurse communicated that he/she had accurately understood my concerns; and the nurse addressed me with my name not just as "just a number") as (69.4\%; 68.7;\%and $68 \%$ ) respectively, while $(60.7 \%)$ of them poor response for item (looking at the notes or computer or anything around herself). 


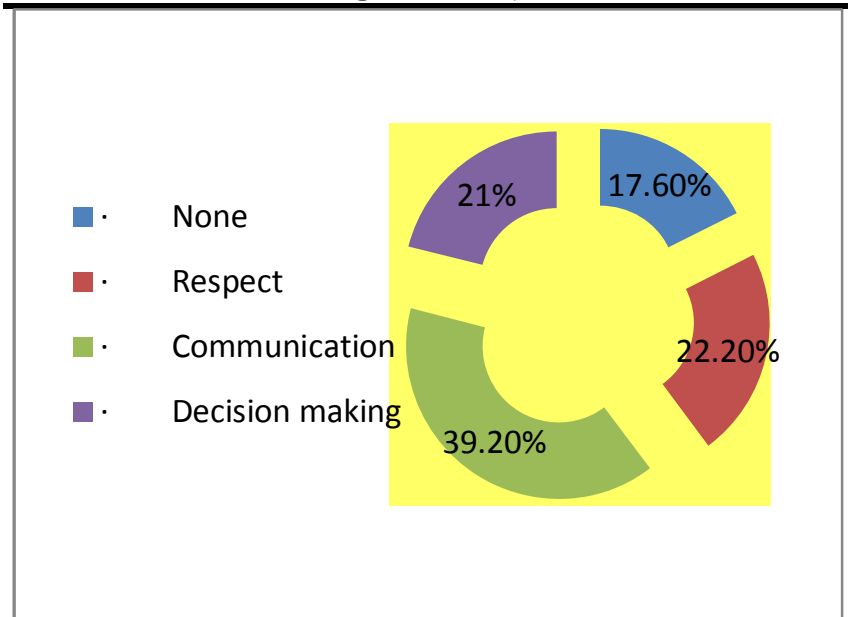

Figure (9) percentage distribution of patient's recommendations regarding their satisfaction at General Hospital (no.=147)

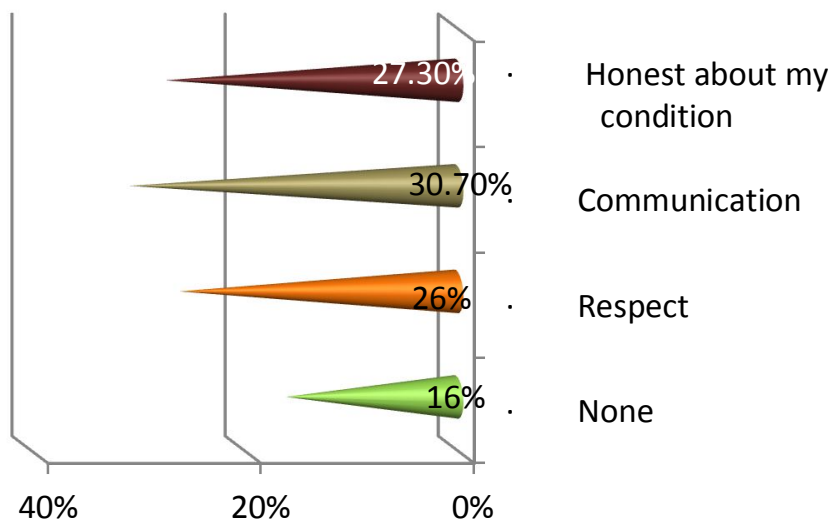

Figure (10) percentage distribution of patient's recommendations regarding their satisfaction at Minia University Hospital $\quad($ no. $=150)$

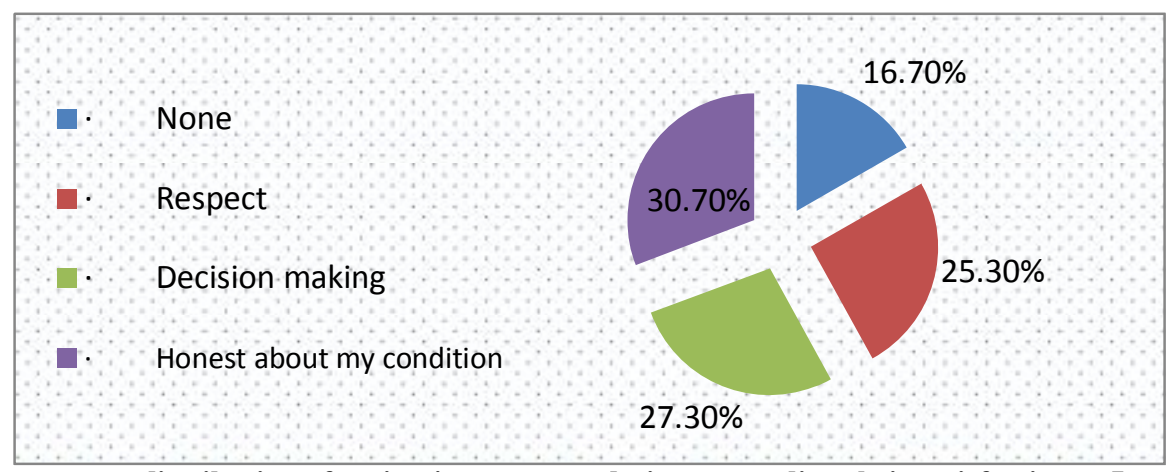

Figure (11) percentage distribution of patient's recommendations regarding their satisfaction at Insurance Hospital (no.=150)

Figure (9) illustrates that most recommendations of patients regarding their satisfaction at Minia General Hospital are " communication with nurses; respect from nurses and share in decision making) as $(39.20 \%, 22.20 \%$, 21\%) respectively. Figure (10) illustrates that most recommendations of patients regarding their satisfaction at Minia University Hospital are " communication with nurses; honest about their conditions and respect from them) as $(30.70 \%, 27.30 \%, \& 26 \%)$ respectively. Moreover figure (11) illustrates that most recommendations of patients regarding their satisfaction at Health Insurance Hospital are " honest about their conditions; share in decision making and respect) as $(30.70 \%, 27.30 \%, \& 25.3 \%)$ respectively.

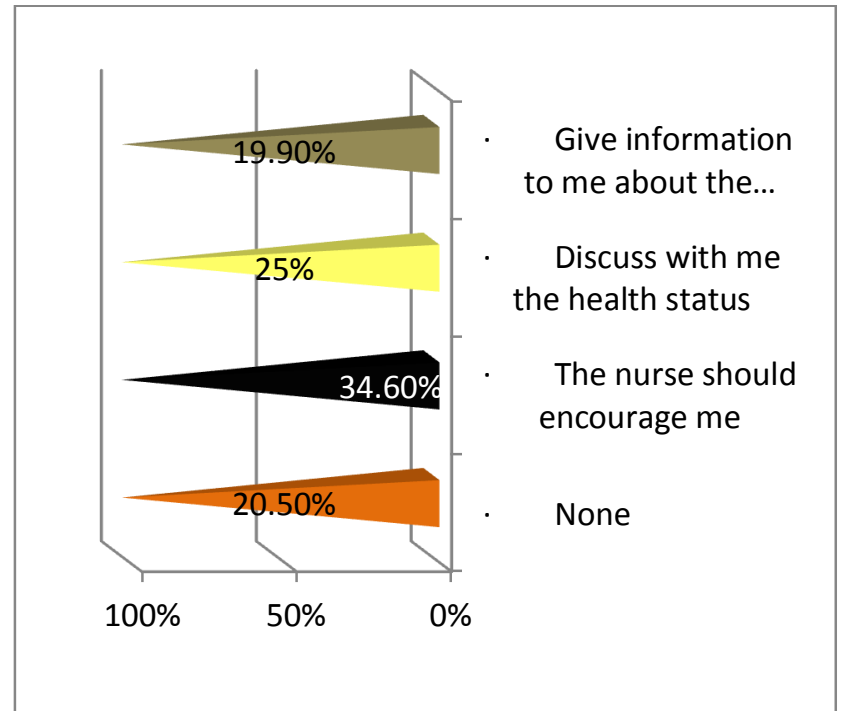

Figure (12) percentage distribution of patient's suggestions regarding their satisfaction at General Hospital (no.=147)

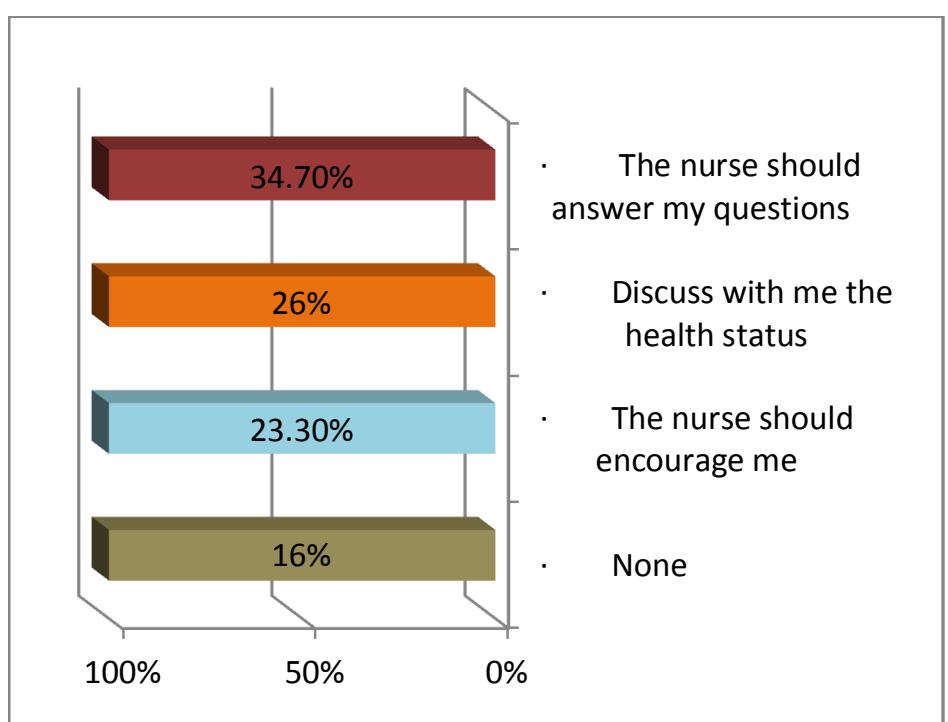

Figure (13) percentage distribution of patient suggestions regarding their satisfaction at Minia University Hospital (no.=150) 


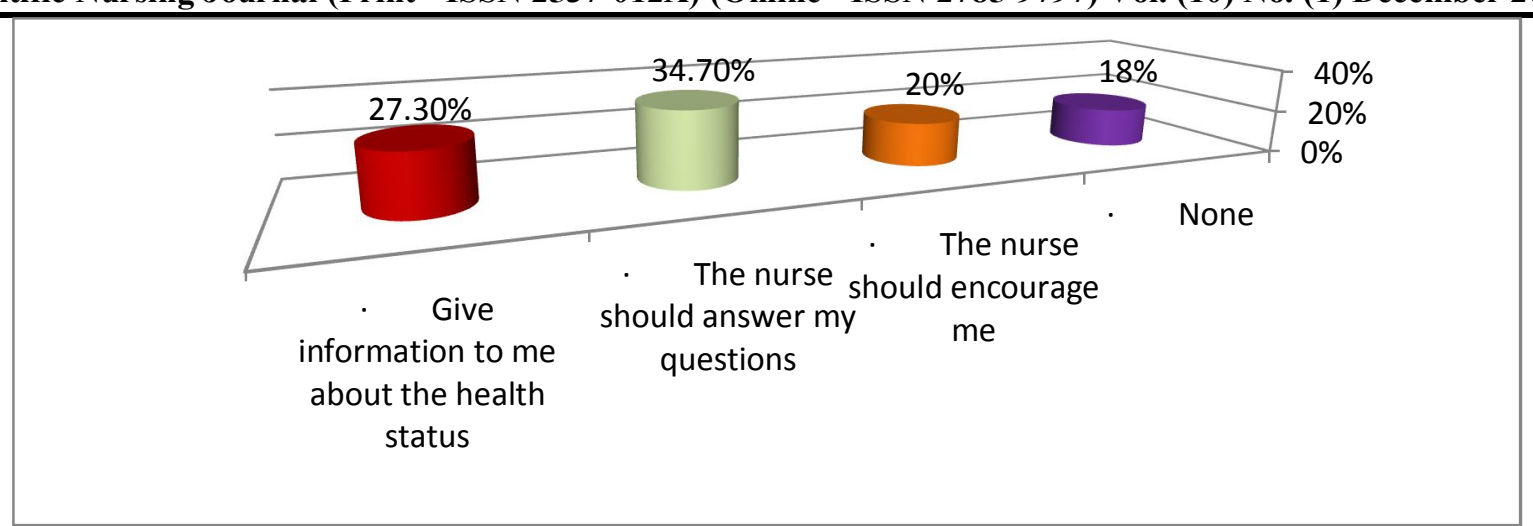

Figure (14) percentage distribution of patient's suggestions regarding their satisfaction at Insurance Hospital (no.=150)

Figure (12) illustrates that most suggestions of patients regarding their satisfaction at Minia General Hospital are " the nurses should encourage them for expression their feeling; discuss with them their health status; and give them formations about health status) as $(34.6 \%, 25 \% \& 19.9 \%)$ respectively. Moreover figure (13) illustrates that most suggestions of patients regarding their satisfaction at Minia University Hospital are " the nurses should answer their questions truly; discuss with them their health status; and nurses encourage them as $(34.7 \%, 26 \% \& 23.3 \%)$ respectively. Figure (14) illustrates that most suggestions of patients regarding their satisfaction at Health Insurance Hospital are " the nurses should answer their questions; give information them about their health status; and nurses encourage them) as $(34.7 \%, 27.3 \% \& 20 \%)$ respectively.

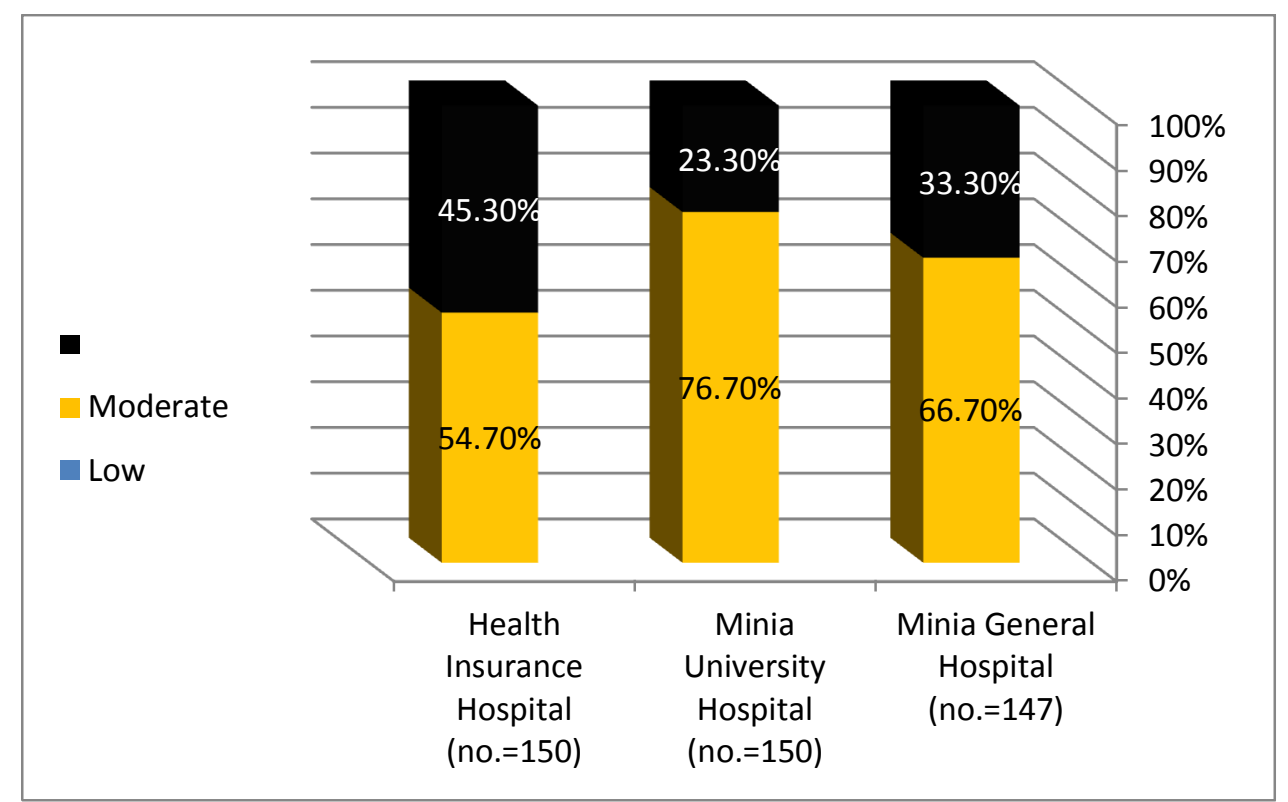

Figure (15) percentage distribution of patient's satisfaction at selected Hospitals (no. $=447)$

Figure (3) shows that the high percent of patients(76.7\%) have moderate level of satisfaction in Minia University Hospital follow by patients in Minia General Hospital as (66.7\%), and finally patients in Health Insurance Hospital as (54.7\%).

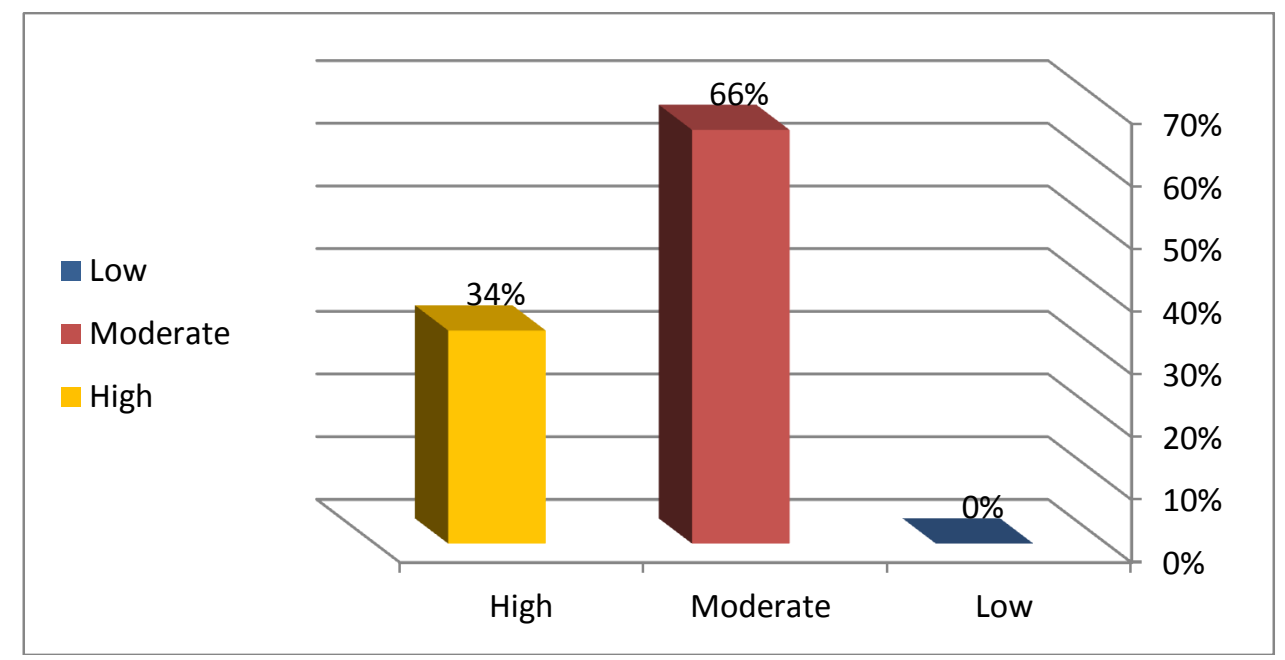

Figure (16) percentage distribution of patient's total satisfaction at selected Hospitals $($ no. $=447)$ 
Figure (4) explains that the majority of patients (66\%) have moderate level of satisfaction in selected Hospitals, while (34\%) of them have high level of satisfaction.

Table (5) correlation between nurses' motivational factor and patient's satisfaction

\begin{tabular}{|l|l|l|l|}
\hline Variable & $\mathbf{r}$ & Nurses' motivational factor & patients' satisfaction \\
\hline Motivational factor & $\mathbf{P}$ & 1 & $0.312\left(.004^{* *}\right)$ \\
\hline Patient satisfaction & $\mathbf{r}$ & $0.312\left(.004^{* *}\right)$ & 1 \\
\hline & $\mathbf{P}$ & & \\
\hline
\end{tabular}

${ }^{* *}$ Correlation is significant at the 0.01 level (2-tailed). ${ }^{*} \mathrm{p} \leq 0.05$ (significant) ${ }^{*} \mathrm{p} \leq 0.05$ (highly significant), $\mathrm{PCC}$ : P - value based on Pearson correlation coefficient

Table (5) explains that there is a positive correlation between nurses' motivational factor and patients' satisfaction ( $p$ $=.004 * *)$

\section{Discussion}

Nurses working in any healthcare sector represent the most viable asset that contributes to building a reputation for health institutions and the abundance and flow for patients seeking better health services, but the behaviors of nurses toward organizations as satisfaction, commitment, and decision to stay or to leave the institutions may or may not be affected by organizational design dimensions (structure and culture). The staff nurses affect on the patient satisfaction (Ali\& Helal, 2019).

Nurse's motivation has been linked to and impacted on many issues in the health care system, such as the outcome of care, patient satisfaction and organizational commitment. Nurse role considered as very important to provide health care for patient with respect the improving the quality of care in health institutions (Salem et al., 2016). Nurses, as the main and large group of health care providers their job performance is affected by job satisfaction and organizational commitment, engaged and satisfied nurses usually perform highly and contribute to organizational efficiency and success (Al-Jabari \& Ghazzawi, 2019).

Patient safety is the cornerstone of high-quality healthcare. Nurses are critical to the surveillance and coordination that reduced such adverse outcomes. End stage renal diseases can result from various hereditary and acquired kidney diseases, it is a major cause of mortality, and is associated with compromised quality of life, high mortality and high burden of illness (Coleman ,2013).

Therefore, the aim of this study was to assess relationship between nurses' motivation and patients' satisfaction in dialysis units

Regarding personal data of staff nurses; the current study showed according Minia General Hospital about three quarters of nurses age were ranged from 20$<40$ years old, with mean age $38.16+0.364$, more than half of them were males. Concerning the education, it noted that more than half of them had diploma degree. about two thirds of them were married. Regarding nurses years of experience one third had $1<10$ years, with mean $(8.13+0.652)$. Moreover the majority of them no patient die in their shift. Also more than half of them from rural area. In addition nurses at Minia University Hospital, less than two thirds of them age were ranged from $20-<40$ years old, with mean age $39.16+0.524$, less three quarters of them were females. Concerning the education, it noted that more than one third had technical degree. The high percent of them were married. Regarding nurses years of experience less than half of them had $1<10$ years, with mean $(9.13+0.212)$. Moreover more than half of them no patient die in their shift. Also about two thirds of them from rural area. Concerning Health Insurance Hospital, more than one third of nurses age were ranged from 20-
$<40$ years old, with mean age $39.16+0.214$, about two thirds of them were females. Concerning the education, it noted that less than half of them had diploma degree. More than half of them were married. Regarding nurses years of experience less than one third were 10-20years, with mean $(10.13+0.432)$. Moreover more than half of them no patient die in their shift. Also more than half of them of them from urban area.

Regarding personal data of patients; current results illustrated that, according Minia General Hospital more than half of patients age were ranged from $40-<60$ years old, with mean age 33. $16+0.372$, more than half of them were males. Also the majority of them were married. Concerning the education, it noted that more than one third had of them high education. About one quarter of the hospital patients stay are $<5$ days, with mean $(4.12+0.354)$. In addition patient at Minia University Hospital, less than half of patients age were ranged from $40-<60$ years old, with mean age $35.16+0.472$, more than two thirds of them were males. Also the majority of them are married . Concerning the education, it notes that one quarter of them had high education. More one quarter of the hospital patients stay are 10-15 days, with mean (7. $12+0.244)$.Concerning Health Insurance Hospital, half of patients age are ranged from $40-<60$ years old, with mean age 32. $16+0.572$, more than two thirds of patients are males. Also the majority of them are married. Concerning the education, it noted that less than one third of them had secondary and high education. About one third of the hospital patients stay are 10-15 days, with mean $(9.12+0.324)$.

The present results revealed that the majority of nurses had moderate level of motivational factors at Minia University Hospital followed by nurses in Health Insurance Hospital, and finally nurses in Minia General Hospital. The researcher point of view Minia University Hospital had more flaw rate of cases with different emergency situation during dialysis, which lead to nourish nurse staff with more skills and knowledge that result in motivate the staff, while nurses in Health Insurance Hospital had more compensation and incentive, but nurses in Minia General Hospital had little of equipment and supplies.

This was harmony with Armstrong (2012), who stated that the motivation can be seen as acting for the satisfaction that derives from doing such activity and job done rather than the rewards granted for doing it. While extrinsic motivation develops from the connection between carrying out an activity to achieve a distinguishable outcome. Moreover Mahmud et al., (2018), stated that the incentive payment can increase employee motivation, loyalty, productivity of the organization and the relationship between employees. Hence, incentive can be a motive for employee to improve their work ability. In addition, work motivation can give positive impact in enhancing performance. 
Also Deussom et al., (2012) stated that there are many reasons health workers remain motivated and decide to stay at their jobs. Generally, a health worker will be motivated and express job satisfaction if they feel that they are effective at their jobs and performing well. Factors contributing to motivation and job satisfaction also include strong career development, an adequate compensation, and adequate working and living conditions. In addition Talukdar, (2012) stated that incentive theory embraces that managers and employees will be more diligent in their work if they are given the promise of additional material and other amenities

Moreover Ojakaa et al., (2018), mentioned that Insuring health workers feel safe at their job is also important to motivation, productivity and their decision to remain at work. This includes such issues as providing health workers access to clean water; insuring workers have adequate supplies of safety equipment and are trained to handle chemicals properly; further, making minor adjustments to the physical environment such as increasing ergonomics of equipment and decreasing the amount of heavy lifting for health workers decreases the amount of absenteeism

The majority of nurses had moderate level of motivational factors, while the minority of them had high level of motivational factors, from the researcher point of view the nurses' had some factors enhance motivation for them but had some recommendations and suggestions, they need to meet its for increasing the motivation of them this reflect on quality care and achieve organization goal.

This was harmony with Engeda et al., (2014) stated that poorly motivated health workers can have a negative impact on individual facilities and an entire health system. Ongori et al., (2021) added that inversely, problems with career development, salary and working/living conditions are also reasons health workers become unmotivated.

Regarding patient satisfaction in the selected hospitals, shows that more than three quarters of patients had moderate level of satisfaction in Minia University Hospital follow by two thirds of patients in Minia General Hospital and finally more than half of patients in Health Insurance Hospital, from the researcher point of view the nurse well communicated and had accurately understood with concerns of the patient in Minia University Hospitals, while the nurse was explaining clearly what the patient was supposed to do in Minia General Hospital, moreover the nurse was positively had positive attitudes and addressed the patient with name when deal with him in Health Insurance Hospital

This fining agreed with Shinde and Kapurkar, (2014) Goh et al., (2016), they stated that measures of patient satisfaction can assess communication in the consultation such as information transfer, patient involvement in decisions and reassurance. Also Teke et al., (2017) who reported that he noticed during his work that patient called the nurse into his room several times during treatment course and the nurse welcomed that without anger and answered all questions to relieve the patient worry concerning his situation. Moreover Reck, (2013);Goh et al., (2016) they mentioned that patients' satisfaction with nursing care has become an established as the most important predictor of the overall satisfaction with hospital care and an important goal of any healthcare organization.

Regarding patient total satisfaction in the selected hospitals, two thirds of patients had moderate level of satisfaction, while the one third of them had high level of satisfaction, from the researcher point of view the patient' had some recommendations and suggestions, they need to meet its for increasing the satisfaction of them this reflect on their health status.

These findings come in the same line with Abou Zeina et al., (2013); and Elsayed et al., (2013) who mentioned in their studies that patients reach to the level of satisfaction regarding the variety of care in any health care facility by completing some expectations regarding his health status and his humanity and rights. Moreover Abd-El-Aziz and Wahab, (2019) reveled that patients were moderately satisfied with quality of care.

The present result showed that there was positive correlation between nurses' motivational factor and patients' satisfaction, from the researcher point of view the nurse motivation encourage nurses' satisfaction and high quality of nursing care which reflect on patients' satisfaction. This result supported by Janicijevic et al., (2013) who mentioned that healthcare worker satisfaction has a significant impact on patient satisfaction. Moreover Lu et al., (2019) enumerated that healthcare worker job satisfaction is a very important parameter that influences productivity as well as quality of work.

\section{Conclusion}

The majority of staff nurses had moderate level of motivational factors in selected Hospitals, while the minority of them had high level of motivational factors. Moreover the two thirds of patients have moderate level of satisfaction in the selected Hospitals (Minia General Hospital, Minia University Hospital and Health Insurance Hospital), while one third of them have high level of satisfaction. Also positive correlation between nurses' motivation factors and patients' satisfaction in the selected Hospitals.

\section{Recommendations}

- The hospital should establish multidisciplinary motivation teams which will be responsible for care of the careers. The team would also be responsible in conducting meetings and facilitate in exploring other means of motivating the nurses.

- The nursing care should continually involve the patients in their care in order to individualize the care.

- Nurses should continually provide information to their clients / patients because this helps the patients in making an informed decision pertaining to the management of their chronic illness.

- It is highly recommended that the study should be carried out to find out patients' contributions towards nurses motivation.

\section{References}

(1) Abd-El-Aziz, N. A., \& Wahab, E. A. (2019). The relationship between staff nurses' satisfaction with their schedule and patients' satisfaction with quality of care. Egyptian Nursing Journal, 16(3), 147.

(2) Abou Zeina HA, El Nouman AA, Zayed MA, Hifnawy T, El Shabrawy EM, El Tahlawy E. ( 2013 ). Patients' rights and satisfaction level: A hospital survey in South Egypt. J Empir Res Hum Res Ethics 8(3), 46-52.

(3) Adhikary, G., Shawon, M. S. R., Ali, M. W., Shamsuzzaman, M., Ahmed, S., Shackelford, K. A., ... \& Uddin, M. J. (2018). Factors influencing patients' satisfaction at different levels of health facilities in 
Bangladesh: Results from patient exit interviews. PloS one, 13(5), e0196643.

(4) Ali, K.A. \& Helal, W.E. (2019). Impact of the organizational design on the organizational behaviors of nurses among healthcare sectors. IOSR Journal of Nursing and Health Science (IOSR-JNHS); 8(6): 63-81.

(5) Al-Jabari, B., \& Ghazzawi, I. (2019). Organizational Commitment: A Review of the Conceptual and Empirical Literature and a Research Agenda. International Leadership Journal, 11(1).

(6) Aly, N. A. E. F. M., \& El-Shanawany, S. M. (2016). The influence of performance appraisal satisfaction on nurses' motivation and their work outcomes in critical care and toxicology units. European Scientific Journal, 12(20).

(7) Armstrong, M. (2012). Armstrong's Handbook of Human Resource Management Practice 12th ed. London: Kogan Page Ltd.

(8) Bakan, I., Buyukbese, T., \& Ersahan, B. (2014). The impact of total quality service (TQS) on healthcare and patient satisfaction: An empirical study of Turkish private and public hospitals. The International journal of health planning and management, 29(3), 292-315.

(9) Baljoon, R. A., Banjar, H. E., \& Banakhar, M. A. (2018). Nurses' work motivation and the factors affecting It: A scoping review. International Journal of Nursing \& Clinical Practices, 5(1).

(10) Batbaatar, E., Dorjdagva, J., Luvsannyam, A., \& Amenta, P. (2015). Conceptualisation of patient satisfaction: a systematic narrative literature review. Perspectives in Public Health, 135(5), 243-250.

(11) Coleman, J., \& Safety, I. P. (2013). Infection Control Through Electronic Prescribing. In Patient Safety Forum.

(12) Demirhan, B. S. (2020). The Effect of Leadership Behaviours of Nurse Managers on Nurses' Work Motivation. International Journal of Caring Sciences, 13(1), 381-391.

(13) Deussom, R., Jaskiewicz, W., Dwyer, S., \& Tulenko, K. (2012). Holding health workers accountable: governance approaches to reducing absenteeism. Technical Brief, 3.

(14) Elsayed AK, El-Melegy A O, El-Zeftawy MA. (2013). The effect of an educational intervention on nurses' awareness about Patients' Rights and satisfaction in Tanta. Journal of American Science 9(9), 210-219.

(15) Engeda, E. H., Birhanu, A. M., \& Alene, K. A. (2014). Intent to stay in the nursing profession and associated factors among nurses working in Amhara Regional State Referral Hospitals, Ethiopia. BMC nursing, 13(1), 1-8.

(16) Fouad, E. R., Abdelrahman, S. M., \& Mohamed, E. A. (2020). Nurses Compliance Toward Patients' Rights and its Relation To Patients Satisfaction. Minia Scientific Nursing Journal, 7(1), 44-53.

(17) Goh, M. L., Ang, E. N., Chan, Y. H., He, H. G., \& Vehviläinen-Julkunen, K. (2016). A descriptive quantitative study on multi-ethnic patient satisfaction with nursing care measured by the Revised Humane Caring Scale. Applied Nursing Research, 31, 126-131.

(18) Hee, O. C., \& Kamaludin, N. H. B. (2016). Motivation and Job Performance among Nurses in the Private Hospitals in Malaysia. International Journal of Caring Sciences, 9(1).

(19) Janicijevic, I., Seke, K., Djokovic, A., \& Filipovic, T. (2013). Healthcare workers satisfaction and patient satisfaction-where is the linkage?. Hippokratia, 17(2), 157.
(20) Kantek, F., Yildirim, N., \& Kavla, İ. (2015). Nurses' perceptions of motivational factors: a case study in a Turkish university hospital. Journal of nursing management, 23(5), 674-681.

(21) Koç, Z., Sağlam, Z., \& Şenol, M. (2011). Patient satisfaction with the nursing care in hospital. Türkiye Klinikleri Journal of Medical Sciences, 31(3), 629-640. .1641322164132216413

(22) Laschinger, H. K. S. (2008). Effect of empowerment on professional practice environments, work satisfaction, and patient care quality: Further testing the nursing worklife model. Journal of nursing care quality, 23(4), 322-330.

(23) Lu, H., Zhao, Y., \& While, A. (2019). Job satisfaction among hospital nurses: A literature review. International journal of nursing studies, 94, 21-31.

(24) Mahmud, A., Hidayah, R., \& Widhiastuti, R. (2018). Remuneration, motivation, and performance: employee perspectives. KnE Social Sciences, 68-76.

(25) McCrory, G., Patton, D., Moore, Z., O'Connor, T., \& Nugent, L. (2018). The impact of advanced nurse practitioners on patient outcomes in chronic kidney disease: a systematic review. Journal of renal care, 44(4), 197-209.

(26) Moffatt, H., Moorhouse, P., Mallery, L., Landry, D., \& Tennankore, K. (2018). Using the Frailty Assessment for Care Planning Tool (FACT) to screen elderly chronic kidney disease patients for frailty: the nurse experience. Clinical interventions in aging, 13, 843.

(27) Ojakaa, D., Olango, S., \& Jarvis, J. (2018). Factors affecting motivation and retention of primary health care workers in three disparate regions in Kenya. Human resources for health, 12(1), 1-13.

(28) Ongori, J., Muiruri, N., \& Vasco, K. (2021). The Influence Of Motivation On The Performance Of Nursing Officers In Devolved Units, A Case Of Nyeri County, KENYA. Journal of Health, Medicine and Nursing, 7(1), 19-36.

(29) Reck, D. L. (2013). Can and should nurses be aware of patients' expectations for their nursing care? Nursing Administration Quarterly, 37(2), 109-115.

(30) Salem, O. A., Baddar, F., \& AL-Mugatti, H. M. (2016). Relationship between nurses job satisfaction and organizational commitment. Journal of Nursing and Health Science, 5(1), 49-55.

(31) Shinde, M., \& Kapurkar, K. (2014). Patient's satisfaction with nursing care provided in selected areas of tertiary care hospital. International Journal of Science and Research, $3(2), 150-160$.

(32) Simeza, D. M. (2013). Impact of nurses' motivation on patients' outcomes: a case study of renal unit at Kenyatta national hospital, Nairobi-kenya (Doctoral dissertation).

(33) Talukdar, A. (2012). Impact of performance pay on enhanced employee performance: mediating role of work motivation and pay satisfaction. Journal for International Business and Entrepreneurship Development, 6(3-4), 303329.

(34) Teke A, Uçar M, Demir C, Çelen O, Karaalp T. (2017). Evaluation of knowledge and attitudes of the nurses working in a training hospital about patients rights. TAF Prev Med Bull; 6(4):259-66.

(35) Whitaker, M. K. (2011).Motivation Checklist; About Leaders making a difference, 2011: 5 (6). 